Work, employment and society

\title{
Labour casualization and the psychosocial health of workers in Australia
}

\section{Michael McGann}

The University of Melbourne, Australia

\section{Kevin White}

The Australian National University, Australia

\section{Jeremy Moss}

The University of New South Wales, Australia

\begin{abstract}
This article presents the results of a qualitative study of 72 workers in regional Victoria, Australia. Against the background of the growing casualization of the workforce it demonstrates the impact on the health and well-being of these workers, focusing on the intersection between psychosocial working conditions and health. In particular it focuses on the detrimental impact on workers' sense of self-efficacy and self-esteem. It emphasizes how the job insecurity characteristic of nonstandard work extends beyond the fear of job loss to involve uncertainty over the scheduling of work, with debilitating consequences for workers' autonomy, self-efficacy and control over their lives. Additionally, it is argued that the exclusion of these workers from paid leave and other entitlements in the workplace confers a lower social status on these workers that is corrosive of their self-esteem. It is these key socio-psychological mechanisms that provide the link between insecure work and workers' health.
\end{abstract}

\section{Keywords}

Australia, health, psychosocial, rural, work

\section{Corresponding author:}

Kevin White, School of Sociology, The Australian National University, Haydon Allen Bldg, University Avenue, Canberra, ACT 0200, Australia.

Email:Kevin.White@anu.edu.au 


\section{Introduction}

Employment and working conditions in advanced economies have changed profoundly over recent decades with potentially far reaching implications for people's well-being and quality of life (Benach et al., 2002; Kalleberg, 2011; Koller, 2009). Globalization and technological change have led to a decline in manufacturing jobs and the emergence of what Becker (2002: 3) terms the 'age of human capital' wherein advanced economies must compete to attract high-skilled, knowledge jobs as more and more manufacturing jobs are shifted to low cost economies. Another, and related, change in the nature of work has been the proliferation of various forms of temporary or non-standard employment, which some sociologists have argued is ushering in an 'age of insecurity' characterized 'by more temporary employment, shorter job tenure and widespread fears of job loss' (Tweedie, 2013: 94).

The organization of work that predominated for much of the second half of the 20th century - one based around a 'standard' model of full-time employment for an indefinite period governed by collectively negotiated wages and centrally regulated working conditions - it is argued, has given way to the growth of the contingent labour market of temporary, casual, contract and self-employment (Facey and Eakin, 2010). Nowhere has this been more apparent than in Australia, where the proportion of the workforce engaged in non-standard work is particularly high by OECD standards (Campbell and Burgess, 2001: 173). Around 20 per cent of the Australian workforce is classified as casual employees, meaning that they receive no paid leave entitlements and rarely have any legal guarantee of future employment. A further 10 per cent work as independent contractors (ABS, 2010: 30), meaning they are regarded as self-employed even though they frequently carry out work for other businesses and often only one client business. Besides the large number of casual employees and independent contractors, many full-time employees in Australia are hired on fixed-term contracts (ABS, 2010: 30), which can be as short as a couple of months.

Drawing on qualitative research with non-standard workers in Australia, this article documents these changes in the social organization of work as they have been experienced by a group of workers living in regional Victoria. It explores the implications of working under non-standard employment arrangements for workers' psychosocial health which, as Facey and Eakin (2010: 327) observe, 'has become a focus of concern for those interested in the effects of changing work patterns on health'. This follows concerns that changes in the nature of employment have resulted in work-related insecurity becoming 'more chronic and widespread than in the past' with 'related consequences for stress-induced health' (Scott, 2004: 150, 144). 'The experience of flexible employment itself, and the insecurity and instability associated with it, may be an important source of stress', as Benach et al. (2000: 1316) cautioned in an early contribution on the topic. This raises questions about the pathways through which non-standard forms of employment might affect workers' health and whether growth in these forms of employment has indeed resulted in work-related insecurity becoming more chronic and widespread than in the past. This article identifies the impact on the respondent's sense of self-efficacy and self-esteem as crucial to their poor health. Self-efficacy was coined by Albert Bandura in 1977 to capture an individual's belief in their ability to succeed and manage 
tasks and their sense of control over their life. Self-esteem refers to the confidence that an individual has in their own worth. Both concepts have a shadowy presence in the literature on health and work - this is highlighted in our use of the literature and they are used to organize our empirical findings. The article begins with consideration of the widespread changes in the organization of work and its relation to workers' health.

\section{The age of insecurity?}

The expansion of non-standard employment is associated with a range of factors including the globalization of economic activity, the rise of the service economy, advances in technology, the increase in the labour force participation of women, declining union influence and labour market deregulation (Blyton, 2013; Facey and Eakin, 2010; Koller, 2009). The more competitive market environment fostered by globalization has motivated businesses to secure lower labour market costs and to pursue new management strategies such as 'flexible' or 'lean production' (Aronsson et al., 2002) that are predicated on the development of a core labour force and 'a disposable labour force that can be automated, and/or hired/fired/off-shored depending upon market demand and labour costs' (Castells, 1996: cited in Doogan, 2001: 420). This enables firms to 'react quickly and efficiently to fluctuating market conditions' (Lenz, 1996: 556) although it presupposes access to a 'just in time' workforce (Aronsson et al., 2002: 153) that has been aided by changes in the composition of the labour force, including the entry of more women and other groups with restricted labour market power into the workforce such as lowskilled migrant workers. As Blyton (2013: 892) observes: '[g]roups with restricted labour market power [...] facilitate the growth of low wage and precarious jobs - employers offer such jobs in the knowledge that they can fill them'.

Here the expansion of non-standard employment is often viewed through the prism of dual labour market theory (Conley, 2008; Facey and Eakin, 2010) with high skilled workers competing in core labour markets for primary, high wage jobs and less skilled workers resigned to the secondary labour market for low wage, insecure employment. Critics contend that the escalation of non-standard employment arrangements has resulted in an increase in 'bad jobs' - in terms of pay, working conditions and access to benefits such as pensions, leave entitlements and medical coverage - with workers facing a more polarized and precarious employment system (Kalleberg, 2011; see also Koller, 2009). The upshot according to theorists of the risk society, such as Beck (2000: 3 ), has been 'a redistribution of risks away from the state and the economy towards the individual' as workers 'have come to bear the burden of organisational and economic performance as never before' (Scott, 2004: 145).

This association of non-standard work with the emergence of 'an age of insecurity' has been challenged by commentators such as Fevre (2007: 529, emphasis in original), who argues that the statistical data on perceived job insecurity among workers do not support the hypothesis and indeed point 'towards reduced feelings of insecurity'. For example, in the UK, the proportion of employees who felt at risk of becoming unemployed or losing their jobs moderately declined between the mid-1990s and early 2000s. Doogan (2001) is similarly critical of the idea of an 'age of insecurity', observing that the proportion of long-term employees in the UK actually increased over the 1990s 
when sociologists such as Beck and Castells were prophesizing the 'end of work' (Tweedie, 2013: 94).

Significantly, the survey data upon which Fevre and Doogan base their critique of the 'age of insecurity' do not capture recent economic downturns and how the lack of formal job security associated with non-standard forms of employment is experienced by workers in a tighter labour market. Moreover, as Conley (2008: 731) argues, high levels of temporary employment can exist alongside increased job tenures for others in the same labour market. In this regard, a major concern is that new patterns of work organization have contributed to a more polarized occupational structure 'in which both high-skills, high-pay and low-skills, low-pay jobs have proliferated, but traditional middle-class jobs, jobs that pay a good wage but do not require much education have disappeared' (Jaros, 2013: 895). Although job tenures may have increased for some, this is compatible with the entrenchment of a 'two-tier' workforce and an 'increase in inequality of job rewards' (Kalleberg, 2013: 897, emphasis in original). Conley (2008: 734), for example, points to predominance of non-standard employment relationships in occupations and sectors that are highly gendered and which employ large numbers of migrants and other 'vulnerable workers'. Koller (2009) links the growth of non-standard employment to the rise in social inequality in many advanced economies where the gap in earnings has widened over recent decades. Our focus of concern in this article is whether the proliferation of non-standard employment arrangements may also be contributed to widening social inequalities in health.

\section{Non-standard work and health}

A growing body of research suggests non-standard employment arrangements may have deleterious effects on workers' health (see, for example, Benach et al., 2002; Facey and Eakin, 2010; Quinlan et al., 2001). Much of the concern over the health damaging effects of non-standard employment focuses on objective aspects of these working conditions that increase non-standard workers' exposure to physical environment health hazards. For example, Benach et al. (2002: 405-6) note how non-standard workers:

work more often in painful and tiring positions, are more exposed to intense noise, perform more often repetitive movements, have less freedom to choose when to take personal leave and are far more less likely to be represented on health and safety committees.

Clougherty et al. (2010: 116) similarly observe that a consistent finding of studies on non-standard work and health 'is that workers in non-traditional settings experience more injuries, and more severe injuries (e.g. fatality)' (see also Benach et al., 2007). Other reviews highlight the poor regulatory environment surrounding non-standard employment, noting that temporary workers tend to have 'reduced knowledge of occupational health and safety issues and regulatory responsibilities' (Quinlan et al., 2010: 304; see also Quinlan et al., 2001). Less attention has been paid to understanding how subjective features of workers' experiences of non-standard work, such as their degree of perceived job insecurity, job satisfaction and control over work, may influence their physical and mental health, in particular their self-esteem and sense of self-efficacy. 
Evidence of an association between non-standard employment and job control, understood in terms of decision latitude and the exercise and development of work skills, is inconclusive. However, Scott (2004: 149) argues that conceptualizations of the link between worker autonomy and health need to be expanded to take account of how structural changes in the economy have severely limited the extent to which workers feel they have control over their lives, not just their jobs. According to Marmot (2004: 134), it is precisely the association between job insecurity and the fear of losing control over one's life and access to vital economic resources that mediates the long-established link between job insecurity and ill-health (for a review see Clougherty et al., 2010). For Marmot, the significance of autonomy and being able to exercise control for health extends beyond the workplace. He goes so far as to suggest that it is because the circumstances 'that foster autonomy and control over life, love, happiness, social connectedness' are doled out unequally 'that we have inequalities in health and death' (2004: 14). Wilkinson and Pickett (2009: 43) offer a subtly different reading of the psychosocial mechanisms behind the social gradient in health, emphasizing what a person's position in the social hierarchy means for the possibility of experiencing self-esteem rather than self-efficacy:

If you don't want to feel small, incapable, looked down on or inferior, it is not quite essential to avoid low social status, but the further up the social ladder you are, the easier it becomes to feel a sense of pride, dignity and self-confidence. Social comparisons increasingly show you in a positive light - whether they are comparisons of wealth, education, job status, where you live, holidays, or any other markers of success.

The intersection between people's experience of working conditions and their experience of recognition and self-esteem provides a second important psychosocial pathway through which working conditions affect health. This is demonstrated by the link between effort-reward imbalance at work and a range of health outcomes such as heart disease, diabetes and poorer mental health (Benach et al., 2007; Marmot et al., 1999). The effort-reward imbalance model of job stress posits the employment relationship as a form of social contract based implicitly on the norm of reciprocity in which employees expect that their physical and psychological efforts at work will be rewarded in kind in the form of either money, esteem and recognition from peers, or promotion and job security (Siegrist, 2005). Effort is exerted at work to win respect and confirm or enhance one's social status. When this effort is rewarded employees enjoy a positive experience of self and feel assured of their status as good professionals who contribute and perform, and who are members of a significant social group (work colleagues). However, if reciprocity breaks down, this can elicit 'a sense of being treated unfairly and suffering injustice which afflicts the workers' self-esteem' and health (Siegrist and Marmot, 2004: 1467). Facey and Eakin (2010: 334) caution that low reciprocity may be a feature of workers' subjective experiences of non-standard employment arrangements, particularly in cases 'where workers are unwilling participants in contingent forms of work and/or where their (material and psychosocial) rewards are below those of full-time workers, despite functioning in a similar capacity' (see also Saloniemi et al., 2004: 196-7). 
The remainder of this article considers the association between non-standard employment arrangements and the opportunities available to workers to experience a sense of control and esteem in-and-through their work.

\section{Study and methodology}

The data presented are drawn from qualitative interviews with non-standard workers in regional and rural areas of Victoria, where the incidence of non-standard employment is higher than in metropolitan locations such as Melbourne (Louie et al., 2006: 478). Participants were recruited for the study with the assistance of unions in key industries with large concentrations of non-standard workers, as well as through advertisements placed in local newspapers. The 72 study participants worked under a variety of nonstandard employment arrangements, including 46 casual employees, 12 independent contractors, six fixed-term contract employees and eight permanent 'irregular' workers. This last group self-identified as casuals during the recruitment phase, although they do not fall strictly under the Australian Bureau of Statistics measure of casual employment since they are formally entitled to holiday and sick pay, albeit on a pro rata basis. However, these workers had highly uncertain work schedules and their income and shifts varied substantially from week to week.

With the exception of fixed-term employees, the majority of participants were men (see Table 1). The high proportion of men in casual employment in this study is in contrast to official data on casual employment, although, overall, female participants were more likely to be employed as casuals rather than other forms of non-standard employment. The casual worker participants were more likely to be younger and less educated than other participants. Fixed-term employees were the workers most likely to have completed tertiary education and to work in either professional or managerial occupations. This was in contrast to casual and permanent irregular workers, the vast majority of whom worked as either labourers or machinery operators.

All participants were interviewed at least once, with just over 60 per cent completing a second interview and 42 participants also completing a third interview. The interviews were semi-structured and lasted about 40 minutes on average. Questions sought to unpack how participants experienced the intersection between their working conditions and their subjectivity across two dimensions: practical agency (or self-efficacy) and relational autonomy (or self-esteem). According to Siegrist and Marmot (2004: 1465), these two aspects of positive self-experience 'are of particular importance for well being and health' and mediate the relationship between workers' health and the quality of their experience of psychosocial work conditions. Accordingly, the interview questions explored the connection between participants' employment conditions and the level of autonomy that interviewees enjoyed in their work roles as well as their ability to plan their lives more generally. During the interviews, participants were also asked to reflect on their relationships with co-workers and treatment by management compared with how standard employees were treated within their workplaces.

The majority of interviews were held in a venue away from the interviewee's workplace. All interviews were recorded and transcribed. The data were then coded and analysed using qualitative data analysis software for common patterns emerging from the 
Table I. Characteristics of study participants.

\begin{tabular}{|c|c|c|c|c|c|}
\hline & $\begin{array}{l}\text { Casual } \\
(n=46)\end{array}$ & $\begin{array}{l}\text { Perm. irr. } \\
(n=8)\end{array}$ & $\begin{array}{l}\text { Fix-term } \\
(n=6)\end{array}$ & $\begin{array}{l}\text { Ind. con } \\
(n=12)\end{array}$ & $\begin{array}{l}\text { Total } \\
(n=72)\end{array}$ \\
\hline \multicolumn{6}{|l|}{ Gender } \\
\hline Female & 21 & 3 & 6 & 1 & 31 \\
\hline Male & 25 & 5 & & II & 41 \\
\hline \multicolumn{6}{|l|}{ Industry } \\
\hline Agriculture, forestry and fishing & 22 & & & 6 & 28 \\
\hline Manufacturing & 5 & $\mathrm{I}$ & & & 6 \\
\hline Construction & 1 & & & 4 & 5 \\
\hline Transport and storage & 7 & 5 & & & 12 \\
\hline Communications & & & & 1 & I \\
\hline Education & 3 & & 5 & & 8 \\
\hline Health and community services & 3 & 2 & & & 5 \\
\hline Retail and hospitality & 3 & & & & 3 \\
\hline Finance, insurance and business services & I & & 1 & 1 & 3 \\
\hline Cultural and recreational services & I & & & & I \\
\hline \multicolumn{6}{|l|}{ Occupation } \\
\hline Labourer & 23 & $\mathrm{I}$ & & & 24 \\
\hline Production and transport workers & 8 & 4 & & & 12 \\
\hline Clerical, sales and services workers & 7 & $\mathrm{I}$ & & 2 & 10 \\
\hline Tradesperson and related worker & & & & 7 & 7 \\
\hline Associate professionals & 4 & 2 & & 3 & 9 \\
\hline Managers and professionals & 4 & & 6 & & 10 \\
\hline
\end{tabular}

research participants' different experiences, bearing in mind the need to be sensitive to structural differences between participants engaged in different types of non-standard work. In the excerpts reported below, participants' names and other identifying details have been changed to safeguard their anonymity.

\section{Contented casuals}

A minority of study participants reported positive experiences of non-standard employment in as much as they believed such employment arrangements afforded them an opportunity to earn income without having to be tied to full-time working hours or an ongoing commitment to an employer. However, these 'contented casuals' tended to be far less reliant on the income from their employment than other study participants, whether because they had a partner who worked in more stable employment or because they were semi-retired and working casually to supplement their income. For example, even though Graeme, a casual stevedore in his 50s, could see a number of downsides with working casually, he explained that as he was 'building a house at the moment, [so] it's good that I can just turn down work'. As his wife had a permanent job, Graeme was not as reliant on the income from his job as other participants in the study. Indeed, several of those who valued the 'flexibility' of non-standard work recognized that this 
'flexibility' could be experienced very differently by those entirely reliant on nonstandard work.

Jack was a retiree who took casual jobs driving tractors across Australia 'just for the life experience' and as a way of seeing the world. But he explained that 'it's not something I would have done if I was married with kids'. Lauren, who switched to temping in offices after having children, similarly described how although temp work was a good fit for her: '[y]ou need to make sure you've got a permanent income coming in from somewhere else [...] otherwise you would get really stressed'. This was reflected in stress and anxiety reported by non-standard workers reliant on the income from their jobs. 'You worry a lot', explained Tom, who sub-contracted as a carpenter for one of the major residential builders in Victoria: 'it can make you quite miserable if there is not enough work around and you are trying to make ends meet'. Trish, a single parent who had worked for many years in temporary teaching positions, was heading into another summer without any work:

I end up getting incredibly broke, very depressed, borrow money left right and centre to pay the mortgage, to pay the power, to buy food and then spend the first term paying it all back [...] I'm not suicidal but I feel like it sometimes though, I do. I've actually got bald patches all over my head from just, yeah, anxiety.

\section{Control over work, life and the debilitating effects of uncertainty on self-efficacy}

Epidemiological theorizing and research on the relationship between the psychosocial work environment, worker-autonomy and health has predominantly focused on the domain of job task performance and the level of decision latitude and skill discretion deployed by workers in carrying out their jobs (e.g. Karasek, 1979; Marmot et al., 1997). The exercise of autonomy in the work role is thought to contribute positively to health by providing workers with 'a sense of personal effectiveness' so that he or she 'feels responsible for shaping his or her life and feels an ability to affect the world' (Levine and Rizvi, 2005: 104). While evidence of a negative association between non-standard employment and low control over job task performance is limited, the experiences of participants in this study suggest it is the destabilizing effects of non-standard employment on workers' ability to exercise autonomy and control over their lives more generally (rather than job tasks) that is most concerning for their psychosocial health. Many participants, especially casual and permanent irregular workers, had little control over the scheduling of their work, while the precariousness of their contractual and economic situation meant that they were not in a position to refuse work when it was offered. The dominant experience was a sense of powerlessness; of having absolutely no control over their work patterns and of being given fewer shifts than they wanted or needed to manage financially. For example, Alice, a care attendant working with older people who was classified as a 'permanent casual', described how even though she had to be available to work 30 hours per week if needed, there was no guarantee that she would actually receive 30 hours of work per week (known as a zero-hours contract in the UK): 
We have a contract and that will state that we have a maximum amount of hours that we can do, but we have no control over the minimum hours that they give us. And although we are given a roster each Friday with our weekly hours on it, what tends to happen is that if we're given four hours' notice, those hours can be gone for whatever reason.

The intermittent and uncertain nature of their work scheduling was experienced by participants as depriving them of the temporal and economic resources needed to plan their lives. As Susan, a factory labourer and sole parent explained:

Sometimes I work one day a week, sometimes four days a week, You cannot predict it [...] It's hard to organize your days; you don't know what you're doing from one day to the next. You don't know whether you're going to work next week, kind of thing, you can't make appointments.

Angela, a lone parent who worked as a labourer in a packing shed, described the stress and anxiety caused by not knowing 'where you stand' because 'the next fortnight you might have nothing': '[b]eing in this position, I'm just, I really can't handle it [...] it's making me very sick and I can't afford to get sick'.

For some, the solution to scheduling uncertainty was to work multiple jobs. This was particularly true of those working as stevedores, whether on a casual or permanent irregular basis, who lived their lives permanently on-call. Each day they waited for a text message in the evening notifying them of whether or not they had work the following day. Several, such as John who was also recently divorced, had taken on additional employment - usually on a casual basis - so that they could still earn a living when there was no work available on the docks. However this presented its own problems, as John explained:

You're driving from [employer A] to get to [employer B] to start work straight away. So I'm trying to get changed into fluoros and all that sort of stuff as you're driving, you know waiting at the set of lights, your top's off, your pants are off. And after a while mate, that was just killing me, so I quit that and just relied on this [stevedoring] work [...] [I]t was a gamble I had to take, because it was either a case of I was going to lose both jobs because you know, both sides were getting peeved.

This was exacerbated by the fact that he had custody of his children every other weekend but might have to take shifts on those weekends because he had no guarantee of work during the week:

I had to fight to try and get the kids every second weekend and sometimes there's no work for the whole week, and then there's work on the weekends where I've got the kids, so then I've got to try and shuffle that around as well to try and keep everyone happy, because if I turn around and ask my ex-partner, things are pretty amicable at the moment, but in the past they haven't been where she's just, 'bad luck, don't work', so you know, 'well I don't work, I can't pay you child support'.

A dominant theme was the difficulties that non-standard workers encountered taking time off, both for financial as well as job security reasons. Hugh, a telecommunications 
sub-contractor who was struggling to get enough hours of work, explained that he had not had a holiday in two years and, even then, it was for only a week. 'It's that tight at the moment', he commented: 'you can't afford to take a day off'. Moreover, when he returned from his holiday, his boss 'got a bit shirty' with him for being away, which has made him more reluctant to take time off again in case it upsets his boss and causes him to lose future work. This was something that casual employees, in particular, were also acutely aware of; that 'you don't rock the boat' as Conor, a machinery operator in a milk processing plant, explained:

I've always said, 'If they want you to work, you go to work.' You might have had something really important on today but [...] 'We'll use you today.' I think this is fairly important to discuss this sort of thing. If they'd rung this morning, I'd have gone. I would've had to get [his wife] to say 'we'll postpone it [the interview] or do it another day, whatever, whatever'.

The insecurity caused by non-standard workers' lack of protection against dismissal and the uncertainty of their work scheduling induced stress via the psychosocial pathway of a sense of powerless over their lives. However, their subjective experience of workrelated insecurity also gave rise to behaviours that undermined their health via direct, material pathways. Participants' accounts here highlighted how the material health hazards associated with non-standard employment such as increased risk of occupational injury are often connected to poor psychosocial work conditions. For example, several reported concealing injuries sustained in their jobs because they feared that they would lose their jobs if they reported a workplace accident or injury:

I now have a doctor's report where I have a bulging disk as well. But see the thing too is, you don't report when you get hurt, all right, because if you report to them you've gotten yourself hurt, you're out of there. (Angela, casual labourer)

Trish, a fixed-term teacher, described how she had decided against reporting a bullying colleague because it was coming near the end of her temporary contract, which she feared might not be extended if she made a fuss:

There was one teacher [...] who seemed to take great delight in humiliating me in front of students. That was an example where I wanted to go and complain but I thought if I go to the principal and say anything, I probably won't get employed. I'll be a troublemaker, or thought of as a troublemaker, and I couldn't afford to shut that door, so it was very tricky [...] I don't think I will ever recover from the emotional trauma of that school it was just dreadful but being a single parent I just had to grin and bear it.

Participants reported examples of being threatened with job loss for raising issues with management. In the second year of the study, Ewen was working casually as an engineer on board a maintenance tugboat. Just before the second interview, the tugboat's air-conditioning unit had broken down:

It had gotten to about day 12 or something like that and we got to a point where a couple of the guys were like, 'if the air-con's not fixed, you know, we're not willing to go to sea sort of thing, 
you know'. The company called up and said, you know, like, 'is that the case, give me a yes or no answer, otherwise we'll get someone else to replace you, you know, we'll get crew who will do it sort of thing' [...] It's stinking hot up here, it's 35 degree days pretty much every day, you know. On a steel boat, it gets pretty hot.

Presenteeism was commonly reported by participants, motivated by both the fear of job loss if they did not show up for shifts as well as the economic insecurity caused by the intermittent and uncertain scheduling of their work. Most non-standard workers in this study, with the exception of fixed-term employees and some permanent irregulars, were not eligible for paid leave entitlements:

We've all come into work ill [...] see our manager [...] when she's not well she doesn't come in but she's permanent [...] We've had, well, cold and flu's and some of the teachers have a gastro but they still come in and spread it all around because you wouldn't tell them that's what it is, and you would certainly lose pay [...] That's the way this thing works. We're not going to get paid if we stay away. (Crystal, lone parent and casual aquatics instructor)

Helen, an attendant working with the aged who also suffered from mental illness, explained how she simply could not afford not to go to work when ill even though she was well aware of the risks this presented to her patients and co-workers:

It just makes things difficult when you don't know when you're going to be working next, or when you don't have many shifts and you're crook as a dog [very ill]. It makes the sickness last longer because you're ill for longer, it lingers and you've just got to go because I panic when I can't go to work.

The material and behavioural health pathways through which participants' subjective experience of insecurity affected their health extended beyond coming to work sick and concealing work-related injuries. Clarke et al. (2007) highlight how irregular work scheduling coupled with the ever present possibility of layoff can motivate non-standard workers to forgo or delay looking after their health. There was evidence of this occurring among the participants in this study. For example, an aged care attendant who had since become permanent part-time explained that she had needed a sinus operation while she was working as a casual but had to postpone the operation because she could not afford to take the time off to have it: 'I had to have a sinus operation and that meant I would have been off work for about four weeks. I had to wait until I went permanent part-time.'

\section{Status inequality and health: the impact on self-esteem}

The influence of people's experience of work-related security on their sense of control over life is undoubtedly an important psychosocial pathway through which working conditions affect health. A less studied but no less important psychosocial pathway is the impact that people's subjective experience of working conditions can have on their experience of self-esteem. Positively, the work role can foster self-esteem if it 'enables the person to connect him- or herself with significant others and to receive appropriate feedback for well-accomplished tasks' (Siegrist and Marmot, 2004: 1466). This can buttress 
a person's sense of self-respect and esteem by 'giv[ing] the person benefiting from it a sense of belonging - to a group, a team, or a trade' (Dejours, 2010: 59). Indeed, Wilkinson (1999: 54) suggests that the well-established link between participation in social networks and health partly arises from the fact that having friends and participating regularly in social groups gives people 'a sense of confidence, of reassurance and of self-confirmation, whereas being rejected or not having friends fills one with self-doubt and causes confidence to evaporate'.

Non-standard employment relationships, by their very nature, denote status differences between core and periphery workers as reflected in the reduced entitlements available to non-standard workers compared with permanent employees. This is especially the case for casual workers in Australia who, as a group, are defined by their very exclusion from paid leave entitlements. Additionally, non-standard workers are more likely to be excluded from professional development and training opportunities as well as decision-making processes within workplaces such as meetings (Aronsson et al., 2002). This was the case for the majority of casual workers in this study, although less so for other non-standard workers. As Daniel, a casual labourer in a fisheries factory explained:

you just sort of feel like you're on a lower rung of the ladder [...] because you're not involved in things that happen with full-time employees, whether it's decisions in the workplace or meetings or things like social gatherings after work.

Julia, who worked as an education support worker, spoke of the distinction that management makes between 'the things that they will invite all the sessionals to and the casuals to, and the things that they will invite the real workers to' (emphasis added). 'It does terrible things to your self-esteem', explained Trish, a school teacher, about the fact she 'wasn't invited' to meetings at her work: 'I'm just a nobody basically [...] I do painting on the side, that's my therapy. If I didn't do that I think I would have been locked up a long time ago because it just squashes your self-esteem.'

These workers' accounts suggested that their very employment as non-standard workers was experienced as a form of occupational misrecognition (see also Malenfant et al., 2007). There was a general sense among casual employees, in particular, that they were seen as second class workers with some participants, such as Sandra, who had worked in a number of retail and administration roles, going so far as to say that, as a casual, 'you're not a real person' (Sandra's emphasis). John, a stevedore, recounted how the casual stevedores were seen as 'the bottom feeders' while casual labourers in other industries routinely commented upon the fact they were seen as 'just boots' or 'shit kickers':

But when you're out at smoko or, you know, having your lunch, they'll be talking about, bitching [about] this, bitching [about] that, because they're all unhappy about someone or something that's going on, and there's nothing they can do about it. And that's where you do get stressed out. You do look down at yourself and say, 'OK, we're a bunch of shit kickers'. (Matt, casual labourer)

Tompa et al. (2007: 218) argue that the status differences implied by non-standard employment relationships 'makes this group susceptible to social exclusion by regular 
full- and part-time workers'. Boyce et al. (2007) similarly suggest that non-standard workers are at risk of marginalization by their permanent co-workers if the latter see them as a threat to their own job security. In some cases, the fear that they might be replaced by casual and temporary workers might motivate permanent workers to actively harass and bully non-standard workers so as to force them from the workplace. This was something that a number of casual labourers experienced. As Ruby, who worked as a seasonal labourer in packing sheds explained: '[t]he full-time workers give the casuals a hard time [...] Just say things and be nasty and give them looks. Make you feel uncomfortable if they can, have a bit of a whinge, bitch.' Susan had a similar experience of being intimidated by the permanent workers in the factory where she worked:

It's the way you're treated by the permanents. It's the stress that they cause, it's so much stress. The casuals get on the phone to each other after work to discuss the terrible things that happened during the day. I'm deadly serious. It's like you're debriefing [laughs] and it's how we got treated and who did what and what happened and, we talk about it, and I guess it's a stress relief.

Compared with casuals, social misrecognition of their subjectivity appeared to be less of a concern for participants who were employed as independent contractors. This may have reflected the higher wages that these participants tended to earn compared to participants in casual employment. Moreover, the independent contractors in the study predominantly worked in industries such as construction and agricultural services where employment as an independent contractor was the dominant form of employment. Few worked alongside permanent co-workers who might perceive them as a threat to their own job security, nor did they interpret themselves as being employed on a second class form of contract compared to others within their occupation.

\section{Discussion}

The social circumstances in which people grow up, live, work and age have a profound influence on health, with social inequalities in health reflecting 'the unequal distribution of power, income, goods, and services, globally and nationally' and 'the consequent unfairness in the immediate, visible circumstances of people's lives' (World Health Organization (WHO), 2008: 1). In almost all advanced economies, differences in the quality of people's working conditions accumulate over the life-course to produce major social inequalities in health (Clougherty et al., 2010). This includes not only differences in workers' risk of exposure to physical and environmental health hazards but also differences in the quality of psychosocial working conditions such as the degree of control they have in their jobs and the level of social support available in the workplace (Marmot et al., 1999, 2001; Siegrist and Marmot, 2004).

People's subjective experience of working conditions can lead to ill-health through psychosocial as well as material pathways. If workers feel that their employment is precarious and they fear for their job security they might: come to work sick (Virtanen et al., 2005); accept more dangerous job tasks; or avoid reporting workplace injuries or occupational health concerns (Facey and Eakin, 2010). People's health can also be affected 
by their subjective experience of working conditions via psychosocial pathways that relate to the opportunities that work provides for experiencing feelings of self-efficacy and self-esteem (Siegrist, 2005: 1034). This is illustrated by the association between health and high job strain - the combination of high job demands and low job control over how and when work is performed - which in repeated studies is linked to increased risk of cardiovascular illness, poorer self-related health and depression (Benach et al., 2007: 81). The exercise of control over work is believed to be positively associated with health because, argues Karasek (1979: 303), it 'represents an opportunity to exercise judgement' and so 'enhances the individual's feelings of efficacy and ability to cope with the environment'.

\section{Conclusion}

Workers in Australia are increasingly being engaged under a variety of non-standard employment relationships, with Australia having among the highest incidences of nonstandard or temporary employment in the OECD (Campbell and Burgess, 2001). While this shift in work organization patterns may be benefiting businesses in enabling them to better respond to peaks and troughs in the global demand cycle, the experiences of the non-standard workers reported in this study suggest workers are paying a high price for this change in the nature of work (Facey and Eakin, 2010). The physical occupational environment in which many non-standard workers perform their jobs has been identified in previous studies as a major source of concern, given non-standard workers' much lower rates of participation in occupational health and safety training (Clougherty et al., 2010). This article has highlighted the poor psychosocial work conditions of certain forms of non-standard employment, particularly status inequalities between non-standard and permanent workers - for example, the stigmatization of non-standard workers as 'only casuals' and their exclusion from meetings and training activities as well as, in many cases, leave entitlements - and the debilitating effects of job insecurity and scheduling uncertainty on the autonomy of non-standard workers. The impact on workers' self-esteem and sense of self-efficacy provides the key social pathways to their experience of stress, anxiety and poor health.

While epidemiological research on the connection between worker-autonomy, health and people's subjective experience of working conditions has concentrated on the domain of job task performance (Quinlan et al., 2010), a key contribution of this article is to extend the focus of concern to how people's subjective experience of working conditions spills over into other domains of life to affect their sense of agency and control at a much broader level. In particular, the experiences of the non-standard workers in this study highlight how the combination of perceived job insecurity and the intermittent and uncertain scheduling of work patterns gives rise to psychosocial stress by depriving nonstandard workers of the temporal and economic resources needed to plan their lives. Non-standard workers' subjective experience of job insecurity, work uncertainty and the status inequality implied by their exclusion from many of the rights and entitlements enjoyed by permanent workers corrodes their health via psychosocial pathways related to work as a source of feelings of self-efficacy and self-esteem. However, the effects of non-standard workers' subjective experience of job insecurity on health extend beyond 
psychosocial pathways by motivating behaviours such as coming to work sick, concealing occupational injuries and putting health care on hold that undermine worker health in material and immediate ways.

\section{Funding}

This study was funded through an Australian Research Council Linkage Grant, between VicHealth, the University of Melbourne and the Australian National University.

\section{References}

Aronsson G, Gustafsson K and Dallner M (2002) Work environment and health in different types of temporary jobs. European Journal of Work and Organizational Psychology 11(2): 151-75.

Australian Bureau of Statistics (ABS) (2010) Forms of Employment Survey 63590. Canberra, ACT, Australia: ABS.

Bandura A (1977) Self-efficacy: toward a unifying theory of behavioural change. Psychological Review 84(2): 191-215.

Beck U (2000) The Brave New World of Work. Cambridge: Polity Press.

Becker G (2002) The Age of Human Capital: Education in the Twenty-First Century (ed. EP Lazear). Palo Alto, CA: Hoover Institution Press, 3-8.

Benach J, Amable M, Muntaner C and Benavides FG (2002) The consequences of flexible work for health: are we looking at the right place? Journal of Epidemiology and Community Health 56: 405-6.

Benach J, Benavides FG, Platt S, Diez-Roux A and Muntaner C (2000) The health-damaging potential of new types of flexible employment: a challenge for public health researchers. American Journal of Public Health 90: 1316-7.

Benach J, Muntaner C and Santana V (2007) Employment Conditions and Health Inequalities: Final Report to the WHO Commission on Social Determinants of Health (CSDH). Available at: http://www.who.int/social_determinants/resources/articles/emconet_who_report.pdf (accessed 28 January 2014).

Blyton P (2013) Book review symposium. Work, Employment and Society 27(5): 891-3.

Boyce AS, Ryan AM and Imus AL (2007) 'Temporary worker, permanent loser?': a model of the stigmatisation of temporary workers. Journal of Management 33(1): 5-29.

Campbell I and Burgess J (2001) Casual employment in Australia and temporary employment in Europe: developing a cross-national comparison. Work, Employment and Society 15(01): 171-84.

Castells M (1996) The Network Society. Oxford: Blackwell.

Clarke M, Lewchuk W, de Wolff A and King A (2007) This just isn't sustainable: precarious employment, stress and worker's health. International Journal of Law and Psychiatry 30(4-5): 311-26.

Clougherty JE, Souza K and Cullen MR (2010) Work and its role in shaping the social gradient in health. Annals of the New York Academy of Sciences 1186: 102-24.

Conley H (2008) The nightmare of temporary work: a comment on Fevre. Work, Employment and Society 22: 731-6.

Dejours C (2010) Subjectivity, work, and action. Critical Horizons 7(1): 45-62.

Doogan K (2001) Insecurity and long-term employment. Work, Employment and Society 15: 419-41.

Facey ME and Eakin JM (2010) Contingent work and ill-health: conceptualizing the links. Social Theory and Health 8(4): 326-49. 
Fevre R (2007) Employment insecurity and social theory: the power of nightmares. Work, Employment and Society 21: 517-35.

Jaros S (2013) Book review symposium. Work, Employment and Society 27(5): 895-6.

Kalleberg A (2011) Good Jobs, Bad Jobs: The Rise of Polarised and Precarious Employment Systems in the United States, 1970s to 2000s. New York: Russell Sage Foundation.

Kalleberg A (2013) Book review symposium: response. Work, Employment and Society 27(5): 896-8.

Karasek RA (1979) Job demands, job decision latitude, and mental strain: implications for job redesign. Administrative Science Quarterly 24(2): 285-308.

Koller P (2009) Work and social justice. Analyse \& Kritik 1: 5-24.

Lenz EA (1996) Flexible employment: positive work strategies for the 21st century. Journal of Labor Research 17(4): 555-66.

Levine DP and Rizvi SA (2005) Poverty, Work and Freedom. Cambridge: Cambridge University Press.

Louie AM, Ostry AS, Keegel T, Shoveller J, LaMontagne AD and Quinlan MG (2006) Empirical study of employment arrangements and precariousness in Australia. Relations Industrielles 61(3): 465-89.

Malenfant R, LaRue A and Vézina M (2007) Intermittent work and wellbeing: one foot in the door, one foot out. Current Sociology 55(6): 814-35.

Marmot M (2004) The Status Syndrome. New York: Henry Holt.

Marmot M, Bosma H, Hemingway H, Brunner E and Stansfeld S (1997) Contribution of job control and other risk factors to social variations in coronary heart disease incidence. The Lancet 350: 235-9.

Marmot M, Siegrist J, Theorell T and Feeney A (1999) Health and the psychosocial environment at work. In: Wilkinson R and Marmot M (eds) Social Determinants of Health. New York: Oxford University Press, 105-31.

Marmot M, Shipley M, Brunner E, et al. (2001) Relative contribution of early life and adult socioeconomic factors to adult morbidity in the Whitehall II study. Journal of Epidemiology and Community Health 55: 301-7.

Quinlan M, Mayhew C and Boyle P (2001) The global expansion of precarious employment, work disorganisation, and consequences for occupational health: a review of recent research. International Journal of Health Services 3: 335-414.

Quinlan M, Muntaner C, Solar O, Vergara M, Eijkemans G, Santana V, et al. (2010) Policies and interventions on employment relations and health inequalities. International Journal of Health Services 40(2): 297-307.

Saloniemi A, Virtanen P and Vahtera J (2004) The work environment in fixed-term jobs: are poor psychosocial conditions inevitable? Work, Employment and Society 18(1): 193-208.

Scott HK (2004) Reconceptualising the nature and health consequences of work-related insecurity for the new economy: the decline of workers' power in the flexibility regime. International Journal of Health Services 34(1): 143-53.

Siegrist J (2005) Social reciprocity and health: new scientific evidence and policy implications. Pschoneuroendocrinology 30: 1033-8.

Siegrist J and Marmot M (2004) Health inequalities and the psychosocial environment: two scientific challenges. Social Science \& Medicine 58: 1463-73.

Tompa E, Scott-Marshall H, Dolinschi R, Trevithick S and Bhattacharyya S (2007) Precarious employment experiences and their health consequences: towards a theoretical framework. Work 28(1): 207-24.

Tweedie D (2013) Making sense of insecurity: a defence of Richard Sennett's sociology of work. Work, Employment and Society 27(1): 94-104. 
Virtanen M, Kivimäki M, Joensuu M, Virtanen P, Elovanio M and Vahtera J (2005) Temporary employment and health: a review. International Journal of Epidemiology 34: 610-22.

Wilkinson R (1999) Health, hierarchy and social anxiety. Annals of the New York Academy of Sciences 896(1): 48-63.

Wilkinson R and Pickett K (2009) The Spirit Level. New York: Bloomsbury Press.

World Health Organization (WHO) (2008) Closing the Gap in a Generation: Health Equity through Action on the Social Determinants of Health. Geneva: WHO Commission on Social Determinants of Health.

Michael McGann, a Research Fellow in the University of Melbourne's School of Social and Political Sciences, gained a PhD in Philosophy from Monash University in 2009. He has lectured in the School of Social and Political Sciences at the University of Melbourne, and the School of Philosophy and Bioethics at Monash University. His work addresses the intersection between labour market participation and disadvantage, and the implications of the changing nature of employment for equality.

Kevin White is Reader in Sociology at the Australian National University. Prior to his appointment at ANU he held lectureships at Flinders University of South Australia, Wollongong University and the Victoria University of Wellington, New Zealand. He is a sociologist of health and illness, originally with interests in the history and philosophy of medicine. He also works on the political economy of health care systems, particularly examining the impact of privatization on the health care system and the medical profession.

Jeremy Moss is Professor of Political Philosophy at the University of New South Wales. His main research interests are in political philosophy and moral theory. Current research interests include projects on egalitarian approaches to climate justice and health, the ethics of renewable energy as well as ethics and energy security. He has published several books including: Reassessing Egalitarianism, Climate Change and Social Justice and Climate Change and Justice (forthcoming, Cambridge University Press).

Date submitted December 2013

Date accepted December 2015 